\title{
GEOLOGIA DO LIMITE ENTRE OS TERRENOS ARQUEANOS E O ARCO MAGMÁTICO DE GOIÁS NA REGIÃO DE CHAPADA-CAMPINORTE, GOIÁS
}

\author{
RAUL MINAS KUYMJIAN', CLAUDINEI GOUVEIA DE OLIVEIRA', \\ JOSÉ ELÓI GUIMARÃES CAMPOS ${ }^{1} \&$ CLAUDIA LIMA DE QUEIROZ ${ }^{2}$
}

\begin{abstract}
GEOLOGY OF THE LIMIT BETWEEN ARCHEAN TERRAINS AND THE GOIÁS MAGMATIC ARC IN THE CHAPADA-CAMPINORTE REGION. GOIÁS This paper presents the results of geological mapping undertaken in the ChapadaCampinorte region, northwestern part of the Tocantins Province, which comprises rocks of the Archaean Hidrolina Complex, the Paleoproterozic Campinorte Volcano-sedimentary Sequence, Mesoproterozoic metasediments from the Serra da Mesa Group and Neoproterozoic supracrustal rocks from the Mara Rosa Volcano-sedimentary Sequence. These lithologies were affected by preBrasiliano deformation, as a consequence of north-south compression, followed by the Brasiliano orogenesis. Geochemical and geochronological $\mathrm{Sm} / \mathrm{Nd}$ data indicate that the Campinorte Volcano-sedimentary Sequence was generated in an island-arc environment during the Paleoproterozoic. This geologic environment, and its close association with the Goiás Magmatic Arc (Mara Rosa Volcanosedimentary Sequence) suggest a tectono-metamorphic geologic evolution involving amalgamation due to the Amazonian and São Francisco cratons convergence. Gold mineralizations in the Campinorte Volcano-sedimentary Sequence are hosted by quartz veins controlled by NS strike-slip faults and closely associated to magnetite-rich granites and diorites.
\end{abstract}

Keywords: Paleoproterozoic sequence, structural geology, gold, Campinorte-Alto Horizonte (Chapada).

Resumo A área enfocada localiza-se no setor noroeste da Província Tocantins, no âmbito da qual afloram rochas graníticas arqueanas do Complexo Hidrolina, a Sequência Vulcano-sedimentar Campinorte, de idade paleoproterozóica, rochas metassedimentares mesoproterozóicas do Grupo Serra da Mesa e supracrustais neoproterozóicas da Seqüência Vulcano-sedimentar Mara Rosa. Tais unidades foram submetidas à deformação pré-brasiliana, decorrente da atuação de compressões norte-sul e, posteriormente, afetadas por evento de deformação de estilo e cinemática compatíveis com o Ciclo Orogenético Brasiliano, extensivo na Faixa de Dobramentos Brasília. Dados de litogeoquímica e geocronologia Sm/Nd indicam que a Sequiência Vulcano-sedimentar Campinorte formou-se em ambiente de arco de ilha durante o Paleoproterozóico, e a sua íntima associação com o Arco Magmático de Goiás (Sequiência Vulcanosedimentar Mara Rosa) sugerem um modelo de evolução tectono-metamórfico com amalgamação resultante da convergência dos cratons Amazônico e São Francisco. As ocorrências auríferas existentes no âmbito da Seqüência Vulcano-sedimentar Campinorte são representadas por veios de quartzo condicionados por um sistema transcorrente-NS sub-vertical, ao qual se associam intrusões graníticas e dioritos ricos em magnetita.

Palavras-chave: Sequiência Paleoproterozóica, geologia estrutural, mineralização aurífera, Campinorte-Alto Horizonte (Chapada).

INTRODUÇ̃̃o Aárea estudada no presente trabalho situa-se na porção sul da Província Tocantins, na transição entre o Maciço de Goiás e a porção interna da Faixa Brasília (Fig. 1). Tal área foi alvo de vários trabalhos, os quais enfocaram, sobretudo, a geologia regional: Barbosa et al. (1969) atribuem os litotipos da região ao Grupo Araxá; Machado e Oliveira (1981) consideram as rochas da região Nova-Iguaçú-Campinorte como pertencentes às unidades média e de topo dos greenstone belts arqueanos de Goiás, enquanto que Ribeiro Filho (1981) as consideram como da Seqüência Vulcano-sedimentar Mara Rosa; Ribeiro Filho e Lacerda Filho (1985) interpretam as rochas metassedimentares como correlatas àquelas das sequiências vulcano-sedimentares Juscelância, Palmeirópolis e Indaianópolis; Siqueira et cl. (1987) sugerem que na região ocorrem rochas do greenstone belt de Crixás e da Sequiência Vulcano-sedimentar Mara Rosa: e Kuyumjian (1994) considera a sequiência de supracrustais a leste da Falha Rio dos Bois, feição estrutural mais marcante na região, como correlacionável às porções de topo do greenstone belt Pilar de Goiás.

Ramos Filho et al. (2003) evidenciam, na região de Mara RosaChapada, a existência de dois sistemas regionais com forte mergu-
Iho e rejeito direcional, sendo um sinistral com direção $\mathrm{N} 40^{\circ}-45^{\circ} \mathrm{Ee}$ outro dextral com direção $\mathrm{N} 25^{\circ}-30^{\circ} \mathrm{W}$, resultantes de compressão regional NNW-SSE. Os autores interpretam a falha reversa Rio dos Bois, que posicionou a Sequiência Vulcano-sedimentar Santa Terezinha sobre o Complexo Hidolina, como resultante dessa compressão regional. Uma compressão regional $\mathrm{EW}$, mais antiga, com transporte tectônico para leste, posicionou a Sequiência Vulcanosedimentar Mara Rosa sobre a Seqüência Vulcano-sedimentar Santa Terezinha. Jost et al. (2001) verificaram que, na região situada no limite entre os terrenos arqueano e neoproterozóico na região de Crixás-Cedrolina e Goiás, as rochas neoproterozóicas cavalgam as rochas arqueanas e consistem de uma unidade metassedimentar e outra metavulcano-sedimentar que podem ser divididas em pelo menos três escamas de empurrão que constrastam em associação litológica, padrão estrutural e grau de metamorfismo. Esses autores identificaram vergência dos terrenos neoproterozóicos para sul/sudeste, em contraste com a vergência geral da Faixa Brasília, para leste, em direção ao Cráton São Francisco. Dantas et al. (2001) obtiveram idades U-Pb da ordem de $660 \mathrm{Ma}$ em zircão de rocha metavulcânica félsica interestratificada em xistos da unidade vulcano-sedimentar individualizada por Jost et al. (2001), confir- 

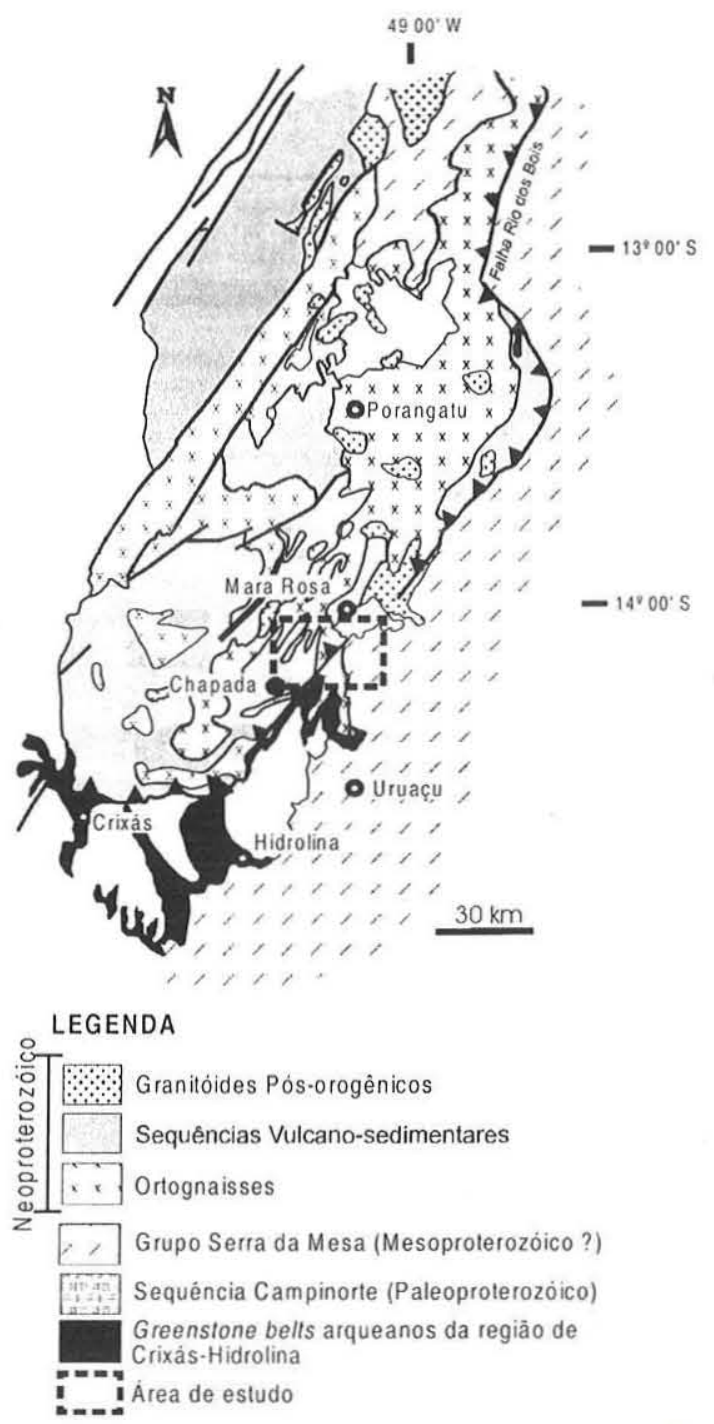

Figura 1 - Localização geográfica e enquadramento geológico regional da área estudada.

mando que as mesmas se formaram durante o Neoproterozóico e, portanto, podem representar extensão meridional do arco magmático. Dantas et al. (2001) também sugerem que a área fonte das rochas da unidade metassedimentar era de idade, predominantemente, paleoproterozóica ou mais velha.

Sínteses sobre as principais características dos depósitos e ocorrências minerais de interesse econômico presentes no Arco Magmático de Goiás são apresentadas por Lacerda (1986), Oliveira et al. (2000) e Kuyumjian (2000), sendo que os dois últimos sugerem, para a formação das mineralizações, evolução contínua de faixa colisional e sistema pórfiro-epitermal, respectivamente.

O presente artigo sintetiza os resultados obtidos durante o trabalho de graduação de alunos do Instituto de Geociências da Universidade de Brasília, o qual consistiu de mapeamento geológico em escala 1:50.000 de uma área de $650 \mathrm{~km}^{2}$ situada no limite entre terrenos arqueano e proterozóico na região de ChapadaCampinorte.

GEOLOGIA LOCAL Unidades tectono-estratigráficas Aárea cartografada no presente trabalho é dominada por extensos platôs, com altitudes em torno de $400 \mathrm{~m}$, desenvolvidos durante o ciclo geomorfológico Velhas. Ainda no estágio de maturidade desse ciclo, perfis lateríticos completos e espessos teriam dominado a paisagem da região. Atualmente, essas crostas lateríticas mostram-se em estágio avançado de degradação, registrada por uma ampla dispersão de solos arenosos lixiviados, fragmentos quartzosos e nódulos lateríticos, que se desenvolveram preferencialmente sobre as seqüência vulcano-sedimentares Mara Rosa e Campinorte . Nas planícies aluviais das principais drenagens da região ocorrem extensos depósitos de argilosos. O Complexo Hidrolina e o Grupo Serra da Mesa afloram nas porções centro-sul e nordeste, onde as cotas são superiores a $500 \mathrm{~m}$ e o relevo é dominado respectivamente por inselbergs e cuestas (Fig. 2).

A Sequiência Campinorte é parte de um contexto geológico regional inédito na literatura sobre a região de Chapada-Mara Rosa, onde idades paleoproterozóicas eram até então desconhecidas. Os autores sugerem que a denominação "Sequiência Vulcanosedimentar Santa Terezinha" não seja mais aplicada para a região, uma vez que a unidade não tem um quadro cronoestratigráfico conhecido e distribuição espacial mal definida. Portanto, não participa das sequiências vulcano-sedimentare arqueanas (greenstone belts) e neoproterozóicas definidas e não é compatível com a unidade paleoproterozóica indivicualizada no presente trabalho.

O Complexo Hidrolina consiste de granodioritos com pouca variação textural e composicional, predominando granodiorito isótropo, médio a grosso, localmente foliado. Por vezes, exibe foliação subvertical, controlada por zonas de cisalhamento, às quais se associa retrometamorfismo da associação mineral ígnea. Plagioclásio e feldspato potássico estão transformados em fengita e biotita em clorita (chamosita). Essas transformações são diagnósticas de metamorfismo da fácies xisto verde. Subordinadamente ocorrem intrusões menores de tonalito e granito, e freqüentes diques de diabásio.

A Seqüência Campinorte inclui metapsamitos (quartzito, muscovita quartzito e quartzo-mica xisto) metapelitos (muscovita xisto, clorita-muscovita xisto com ou sem granada, clorita-biotitacarbonato xisto, muscovita-quartzo xisto e, subordinadamente, xistos carbonosos) e rochas metassedimentares químicas (gondito e metachert) em lentes de dezenas de metros de espessura e centenas de metros a poucos quilômetros de comprimento. Metavulcânicas ácidas são freqüentes e ocorrem como espessos pacotes ou pequenas lentes intercaladas nas rochas metassedimentares. Os litotipos vulcânicos mais representativos e mais freqüentes dessa unidade são rochas piroclásticas ácidas com pronunciado bandamento granulométrico, seguidas de riolitos e riodacitos porfiríticos. Intercalações de metaultramáficas, anfibolito fino e epidoto anfibolito são subordinados. O empilhamento original da seqüência não foi reconhecido uma vez que as unidades são descontínuas em superfície e foram submetidas a intensa deformação. As paragêneses metamórficas, principalmente dos xistos (granada-clorita-muscovita), são da fácies xisto verde. A Sequiência Campinorte contem intrusões de tonalito, granodiorito e granito, metamorfizadas na fácies xisto verde, $\mathrm{e}$ gabro médio a grosso transformado em hornblenda-anfibolito. Tais rochas constituem, provavelmente, equivalentes plutônicas do vulcanismo da Seqüência Campinorte. Diques máficos (metadiabásio e metagabro) e corpos alongados ou semicirculares de pequenas dimensões de rochas ultrabásicas (esteatito e talco xisto) são freqüentes na área.

A Tabela 1 apresenta resultados analíticos de amostras representativas de anfibolito da Seqüência Campinorte e de intrusivas 


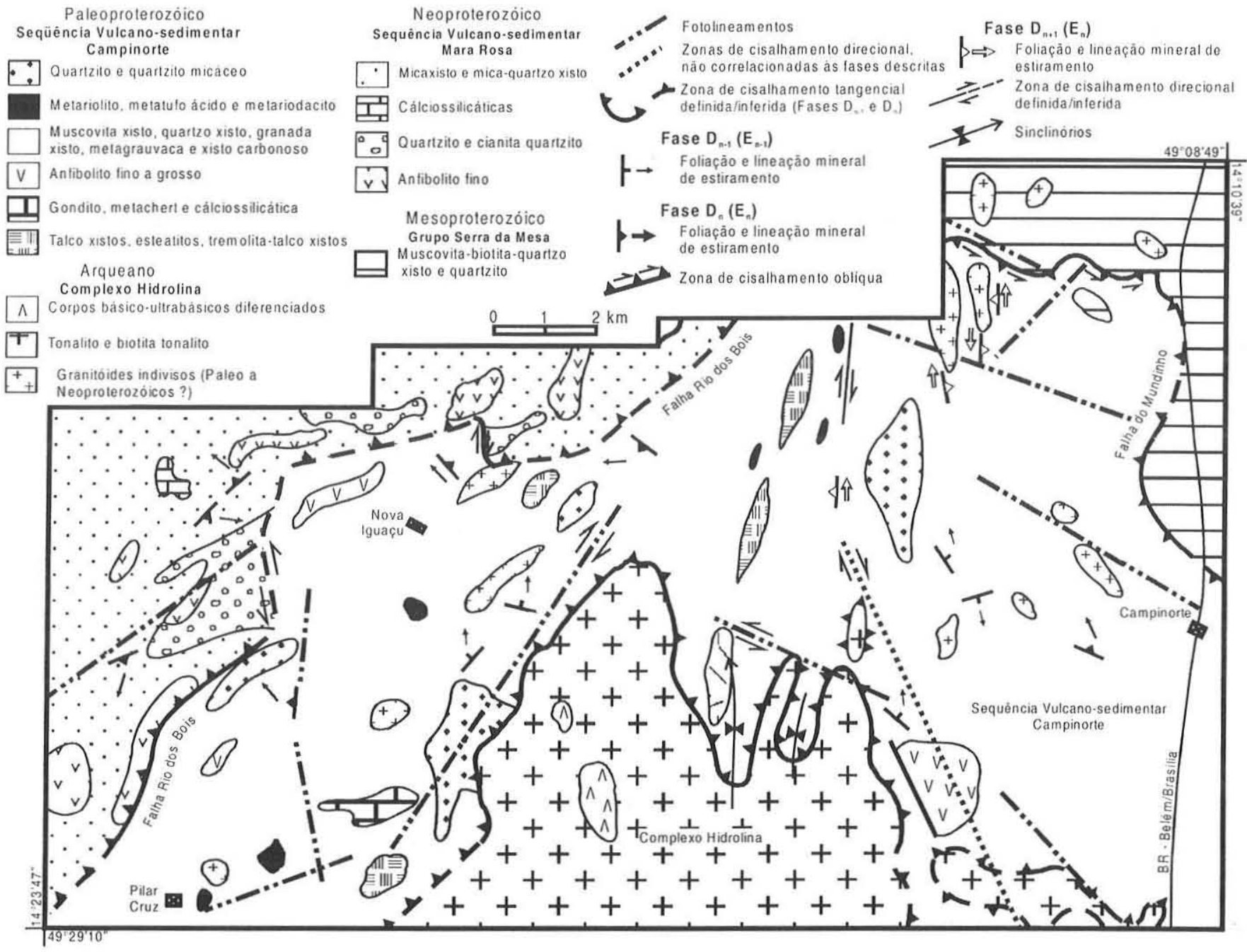

Figura 2 - Mapa geológico da região Chapada-Campinorte, Goiás (modificado de Kuyumjian et al.1997).

ácidas, obtidos por ICP-ES no ACME Analytical Laboratories, Canadá. Diagrama multielementar de duas amostras do anfibolito fino apresenta anomalias negativas de nióbio, indicativas de ambiente do tipo arco de ilha (Fig. 3b). A posição do tonalito, granodiorito e granito no diagrama $\mathrm{Y}-\mathrm{Nb}$ (Fig 3a) e as anomalias negativas de Nb no diagrama multielementar (Fig. 3b) também indicam ambiente de arco de ilha.

Determinações isotópicas $\mathrm{Sm}-\mathrm{Nd}$ em metavulcânicas ácidas e metaplutônicas ácidas foram efetuadas no Laboratório de Geocronologia da Universidade de Brasília, segudo procedimentos propostos por Gioia \& Pimental (2000). Os resultados (Tabela 2) forneceram idade modelo $\left(\mathrm{T}_{\mathrm{DM}}\right)$ entre 2,30 e 2,52 Ga., o que sugere protólitos paleoproterozóicos. Uma isócrona de referência obtida por Oliveira \& Pimentel (1998) em metavulcânicas ácidas e metaplu-tônicas acidas expostas a noroeste de Campinorte, no âmbito da Sequiência Campinorte, indicou idade de $2,371 \pm 138$ Ga e $\varepsilon_{\mathrm{Nd}}(\mathrm{T}) \mathrm{de}+2,4$.

O Grupo Serra da Mesa compõe-se de uma sequiência plataformal monótona constituída, na área estudada, de quarzitos finos a médios e quartzo xistos com muscovita e granada, aflorantes principalmente ao longo da BR-153 (Rodovia Belém-Brasília). As paragêneses metamórficas nestas rochas indicam metamorfismo da fácies xisto verde, transição entre as zonas da clorita e da biotita/ granada. O posicionamento cronoestratigráfico desta unidade é controverso, mas sua distribuição e associação faciológica permitem correlacioná-la ao Grupo Arai, cujas rochas vulcânicas da base foram datadas de 1,79 Ga, pelo método U-Pb em zircões (Pimentel \& Fuck 1992).

A Sequência Mara Rosa aflora na porção noroeste da área mapeada, em região peneplanizada e coberta por concreções ferruginosas lateríticas. Apresenta similaridade litológica e continuidade lateral com as rochas supracrustais expostas a norte, na região de Chapada-Mara Rosa, e padrão geofísico (magnetometria e radiometria), obtido a partir de dados do Projeto Geofísico BrasilCanadá (Carmo 1978), idêntico ao das proximidades da cidade de Mara Rosa. Na área estudada, a seqüência compreende epidoto anfibolito, anfibolito bandado e, localmente, rochas metassedimentares (granada-clorita-quartzo-muscovita xisto, cianita quartzito, granada quartzito feldspático e gondito) da fácies anfibolito.

Geologia Estrutural Os dados estruturais permitem reconhecer dois eventos de deformação $\left(\mathrm{E}_{n-1}\right.$ e $\left.\mathrm{E}_{n}\right)$ responsáveis por, pelo menos, três fases $\left(D_{n-1}\right.$ a $\left.D_{n+1}\right)$. A fase $D_{n-1}$ está representada por lineações minerais e de estiramento, de orientação aproximada NS 
Tabela I - Análises químicas representativas de anfibolito da Seqüência Vulcano-sedimentar Campinorte e de tonalito, diorito

\begin{tabular}{|c|c|c|c|c|c|c|c|c|c|c|c|c|}
\hline & \multicolumn{5}{|c|}{ Anfibolito } & \multicolumn{5}{|c|}{ Tonalito } & Diorito & Granito \\
\hline $\mathrm{SiO}_{2}$ & 48.15 & 48.92 & 49.64 & 51.39 & 54.34 & 74.89 & 74.08 & 72.93 & 71.93 & 61.83 & 69.58 & 74.27 \\
\hline $\mathrm{TiO}_{2}$ & 0.95 & 1.66 & 2.51 & 1.42 & 0.55 & 0.37 & 0.26 & 0.31 & 0.73 & 0.64 & 0.37 & 0.08 \\
\hline $\mathrm{Al}_{2} \mathrm{O}_{3}$ & 12.97 & 15.65 & 15.91 & 18.67 & 15.29 & 14.6 & 1.3 .59 & 13.8 & 12.9 & 16.4 & 13.68 & 15.48 \\
\hline $\mathrm{Fe}_{2} \mathrm{O}_{3}$ & 1.21 & 4.23 & 5.81 & 3.3 .3 & 5.31 & 0.01 & 0.3 & 0.74 & 0.81 & 1.1 & (0.0) & 0.93 \\
\hline $\mathrm{FeO}$ & 9.9 & 7.8 & 7.91 & 7.09 & 4.05 & 1.43 & 2.54 & 2.14 & 2.89 & 4.58 & 3.24 & 0.75 \\
\hline $\mathrm{MgO}$ & 5.78 & 4.97 & 2.9 & 4.57 & 6.37 & 0.44 & 0.4 & 0.88 & 0.66 & 2.99 & 0.97 & 0.38 \\
\hline $\mathrm{C}: \mathrm{O}$ & 8.8 & 8.51 & 8.42 & 8.41 & 6.98 & 2.52 & 0.94 & 2.35 & 2.57 & 4.93 & 1.99 & 0.41 \\
\hline $\mathrm{Na}_{2} \mathrm{O}$ & 1.15 & 1.99 & 2.89 & 2.89 & 3.54 & 3.66 & 2.7 & 3.2 & 2.38 & 3.66 & 3.54 & 3.2 \\
\hline $\mathrm{K}_{2} \mathrm{O}$ & 0.86 & 1.17 & 0.76 & 0.8 & 0.71 & 0.84 & 2.74 & 1.38 & 2.56 & 1.35 & 1.92 & 2.71 \\
\hline $\mathrm{P}_{2} \mathrm{O}_{5}$ & 0.11 & 0.36 & 1.27 & 0.37 & 0.14 & 0.07 & 0.13 & 0.12 & 0.32 & 0.28 & 0.13 & 0.04 \\
\hline $\mathrm{M} n \mathrm{O}$ & 0.32 & 0.15 & 0.28 & 0.17 & 0.14 & 0.02 & 0.07 & 0.05 & 0.05 & 0.09 & 0.02 & 0.03 \\
\hline $\mathrm{PF}$ & 2.05 & 3.8 & 0.73 & 1.17 & 2.64 & 0.35 & 1.58 & 1.12 & 1.38 & 1.58 & 6.38 & 1.02 \\
\hline $\mathrm{Ba}$ & 85 & 724 & 50 & 1.32 & 57 & 883 & 2000 & 1305 & 1531 & 530 & 1956 & 1600 \\
\hline $\mathrm{Sr}$ & 100 & 105 & 103 & 16 & 179 & 621 & 158 & 551 & 230 & 557 & 440 & 124 \\
\hline Y & 23 & 9 & 26 & 6 & 13 & 6 & 42 & 5 & 19 & 9 & 10 & 19 \\
\hline $\mathrm{Nb}$ & 6 & 11 & 8 & 9 & 2 & 8 & 1.3 & 7 & 26 & 9 & 16 & 7 \\
\hline $\mathrm{Zr}$ & 30 & 37 & 85 & 17 & 52 & 75 & 159 & 31 & 200 & 12 & 140 & 1.34 \\
\hline Lat & & & 10.61 & 10.87 & & 22.46 & & & & & 40.32 & 31.18 \\
\hline $\mathrm{Ce}$ & & & 8.6 & 17.89 & & 52.3 & & & & & 81.2 & 66.9 \\
\hline $\mathrm{Nd}$ & & & 10.67 & 12.07 & & 28.47 & & & & & 31.18 & 31.98 \\
\hline$S m$ & & & 1.17 & 1.02 & & 4.39 & & & & & 3.86 & 5.72 \\
\hline Eu & & & 0.96 & 1.33 & & 1.4 & & & & & 1.06 & 2.09 \\
\hline Gd & & & 3.39 & 3.33 & & 3.81 & & & & & 3.24 & 5.72 \\
\hline Dy & & & 2.73 & 2.53 & & 2.29 & & & & & 1.84 & 3.45 \\
\hline Ho & & & 0.67 & 0.52 & & 0.56 & & & & & 0.42 & 0.68 \\
\hline Er & & & 1.99 & 1.53 & & 1.29 & & & & & 0.94 & 1.92 \\
\hline $\mathrm{Yb}$ & & & 1.69 & 1.19 & & 1.04 & & & & & 0.86 & 1.26 \\
\hline Lu & & & 0.25 & 0.27 & & 0.09 & & & & & 0.04 & 0.24 \\
\hline
\end{tabular}

Tabela 2 - Dados isotópicos Sm-Nd de metavulcânica ácida da Seqüência Vulcano-sedimentar Campinorte e metaplutônicas ácidas intrusivas na mesma.

\begin{tabular}{|c|c|c|c|c|c|c|}
\hline Amostra & Rocha & $\begin{array}{c}\mathrm{Sm} \\
(\mathrm{ppm})\end{array}$ & $\begin{array}{c}\text { Nd } \\
(\mathrm{ppm})\end{array}$ & ${ }^{147} \mathrm{Sm}{ }^{1+4} \mathrm{Nd}$ & $\begin{array}{l}{ }^{14.3} \mathrm{Nd}^{1+4} \mathrm{Nd} \\
( \pm 2 \mathrm{SE})\end{array}$ & $\begin{array}{l}T_{1 M} \\
\text { (Ga) }\end{array}$ \\
\hline 65 & Metadi & 8,112 & 39,21 & 0,125 & 0,511633 & 2,42 \\
\hline 127 & Metadacito & 29.10 & 181,56 & 0,097 & 0,511156 & 2.45 \\
\hline 148 & Metadacito & 7,180 & 33,85 & 0,128 & 0,511625 & 2,52 \\
\hline 82 & Metagranito & 3,896 & 17,82 & 0,132 & 0,511806 & 2,30 \\
\hline 165 & Metagranito & 6,088 & 26,46 & 0,139 & 0,511882 & 2,44 \\
\hline
\end{tabular}

e foliação de atitude freqüentemente ajustada ao contato com o Complexo Hidrolina. A relação entre ambas estruturas mostra transporte oblíquo a tangencial, com vergência geral para sul, indicando que a Seqüência Campinorte foi tectonicamente colocada sobre o Complexo Hidrolina nesta fase.

$\mathrm{O}$ evento $\mathrm{E}_{\mathrm{n}-1}$ é interpretado como resultado de esforços compressivos de direção aproximada NS, atuante, provavelmente, no Paleoproterozóico, posto que, na área estudada, seu registro não ocorre na Seqüência Mara Rosa e Grupo Serra da Mesa. Isto sugere que a Sequiência Mara Rosa é mais jovem que a Sequiência Campinorte.

A fase $D$ tem o acervo estrutural mais penetrativo da área estudada. Dobras ocorrem especialmente nas regiões de mais alta magnitude de deformação. São assimétricas, apertadas e de vergência geral para leste. As lineações minerais e de estiramento são consistentes em torno de $\mathrm{N} 60^{\circ} \mathrm{W} / 20^{\circ}$, enquanto a foliação varia entre $\mathrm{N} 20^{\circ}-45^{\circ} \mathrm{E} / 20^{\circ}-35^{\circ} \mathrm{NW}$, indicativas de relação tangencial, com transporte tectônico de baixo caimento, alta obliqüidade e vergência para SE, em direção ao Cráton São Francisco (Fig. 2). Duas falhas de importância regional são atribuídas a essa fase. Uma, a Falha Rio dos Bois, coloca a Sequência Mara Rosa sobre a Sequência Campinorte, com movimento reverso oblíquo dextral, enquanto que a outra, a Falha do Mundinho, menos evidente que a primeira, sobrepõe a Sequência Campinorte sobre o Grupo Serra da Mesa.

Durante a fase $\mathrm{D}_{\mathrm{n}-1}$ foi gerada uma crenulação $\mathrm{N} 10^{\circ} \mathrm{E} / 25^{\circ} \mathrm{W}$, e uma foliação incipiente, com máximo em $\mathrm{N} 40^{\circ} \mathrm{E} / 30^{\circ} \mathrm{NW}$. Localmente ocorre uma intensa lineação de estiramento associada, com direção em torno de NS, baixa obliqüidade e baixo caimento (Fig. 2). Ainda associadas a esta fase, ocorrem zonas de cisalhamento direcionais NS, subverticais e dextrais, interpretadas como zonas de cisalhamento de terceira ordem (sensu Moody \& Hill 1956). Esta fase é interpretada como o registro final do evento $E n$.

O tratamento estatístico dos dados indica ter havido dobramento regional da foliação em duas direções, EW e NS. Interpretase o eixo EW como pertencente ao evento $E_{n-1}$, enquanto o eixo NS seria resultante do evento En, o que pode ter promovido variação no quadrante de caimento das lineaçôes minerais e de estiramento. Isso é, ondulações suaves e de eixo EW podem ser responsáveis por lineações NS (evento $\mathrm{E}_{\mathrm{n}-1}$ ) apresentarem caimento tanto para $\mathrm{N}$ quanto para $\mathrm{S}$. De forma análoga, ondulações de eixo NS podem ter provocado o caimento para NW e para SE das lineações naquela direção (evento En).

Zonas de cisalhamento direcionais NW e NE também ocorrem, mas a escassez de relações de corte e superposição impediram sua inclusão nas fases de deformação descritas.

MINERALIZAÇÕES DE OURO A região cartografada se insere no contexto do distrito auro-cuprífero de Chapada-Mara Rosa (Oliveira et al. 2000). Esse distrito, que vem sendo investigado por companhias de mineração desde o início da década de 70, contém importantes depósitos de Au (Posse), Au-Ag (Zacarias) e Cu-Au (Chapada), além de várias ocorrências de ouro pouco estudadas (Lacerda 1986). Durante esse período, os investimentos em exploração foram condicionados, sobretudo, à flutuação do preço do ouro no mercado internacional. Além disso, esses investimentos se concentraram nas áreas de ocorrências minerais conhecidas (garimpos e minas), sem evolução dos trabalhos de cartografia geológica que sustentasse a continuidade das atividades de prospecção. As ocorrências de ouro da área estudada (garimpos 

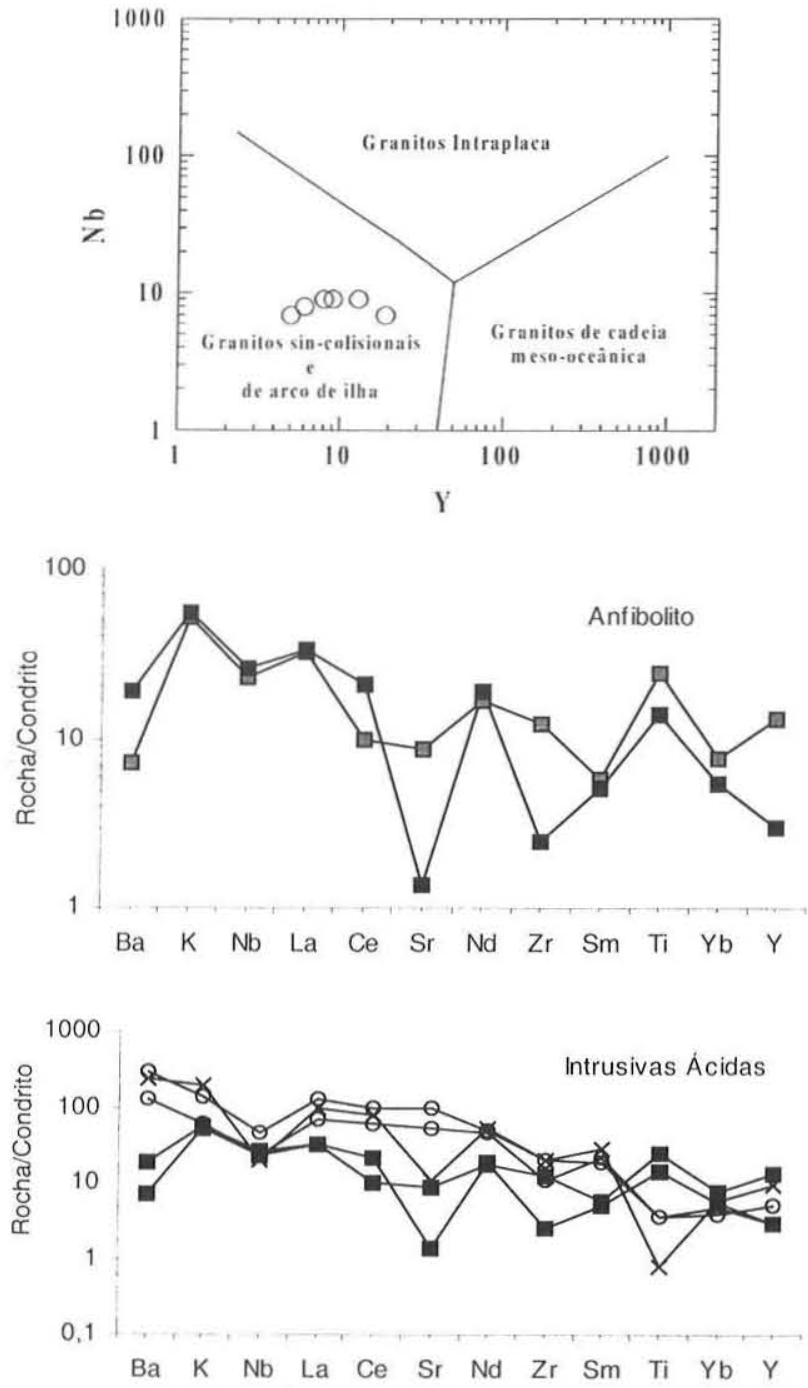

Figura 3 - Diagramas (a) Y-Nb (Pearce et al. 1994) aplicado a intrusivas ácidas da Seqüiência Vulcano-sedimentar Campinorte $e$ (b) multielementares normalizados pelos valores condríticos de Thompson et al. (1984), aplicados a anfibolitos da Seqüiências Vulcano-sedimentar Campinorte e intrusivas granitóides associadas.

do Mundinho e da Viúva) consistem de veios de quartzo controlados por um sistema transcorrente-NS subvertical e hospedados em metaplutônicas (tonalito e granodiorito) elipticas, intrusivas em rochas metapsamo-pelíticas da Sequiência Campinorte (Fig. 4). As encaixantes compreendem quartzito a quartzo xisto, magnetita quartzito a pirita-magnetita-muscovita-quartzo xisto e, subordinadamente, epidoto quartzito a epidosito. As rochas ricas em epidoto, magnetita e pirita são interpretadas como produtos de alteração hidrotermal de um episódio regional de mineralização, ao qual se associam os depósitos de Cu-Au de Chapada e Au-Ag-Ba de Zacarias.

A principal ocorrência de ouro da região é o garimpo do Mundinho, cujo controle estrutural resultou de um evento deformacional que marca acentuada mudança na cinemática e no regime de deformação. Os domínios graníticos anteriormente deformados sob regime dúctil e cinemática dextral, evidenciado pelo

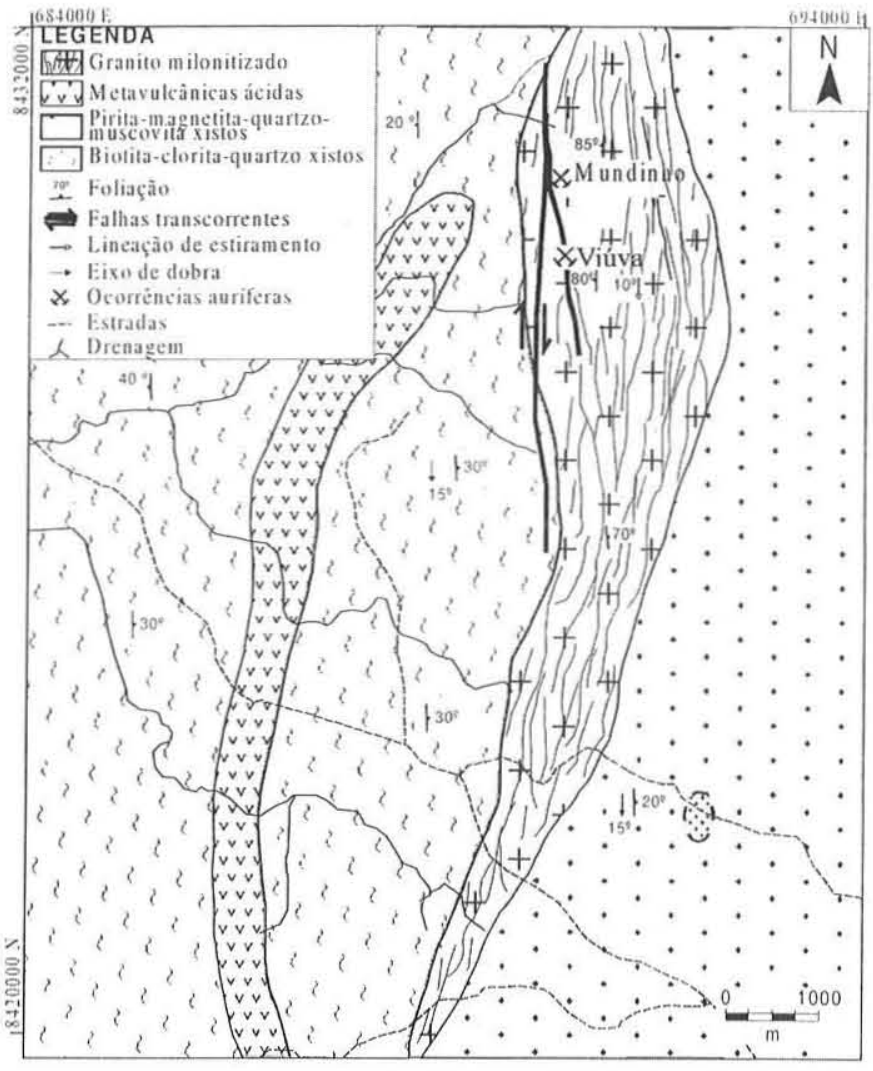

Figura 4-Mapa geológico das ocorrências de ouro associadas ao sistema transcorrente norte-sul, na região de Campinorte.

pronunciado estiramento de porfiroclastos de quartzo e feldspato potássico, foram superimpostos por deformação rúptil a dúctilrúptil. As estruturas associadas a esse evento compreendem bandas de cisalhamento com cinemática sinistral. Esse estágio é marcado por faixas estreitas e irregulares não penetrativas com disseminações de pirita associadas a zonas de biotitização e muscovitização progressiva dos domínios graníticos. Associados a estas alterações ocorreu ainda sulfetação (pirita, calcopirita, bismutinita), carbonatação, formação de magnetita e precipitação de ouro e bismuto. As principais concentrações de ouro ocorrem em veios de quartzo onde a sulfetação foi mais pronunciada. $\mathrm{O}$ ouro ocorre como inclusões na calcopirita e/ou como grãos livres e alongados dispostos segundo a foliação milonítica.

A ocorrência de ouro do Mundinho, além de apresentar um nítido controle estrutural pelo sistema transcorrente NS, está temporal e espacialmente associada às intrusões de granitóides do estágio pós-tectônico da evolução do Arco Magmático de Goiás. A idade dessas intrusões pode ser estimada em torno de $560 \mathrm{Ma}$, tendo como referência uma idade $\mathrm{U} / \mathrm{Pb}$ em titanita, obtida por Pimentel et al. (1997) em um magnetita diorito da suíte intrusiva.

DISCUSSÃOE CONCLUSÃO Na região Chapada-Campinorte, as duas faixas de rochas supracrustais imediatamente a norte do Complexo Hidrolina constituem a extensão sul-sudoeste das seqüências vulcano-sedimentares Mara Rosa e Campinorte na região de Chapada-Mara Rosa. Os dados geocronológicos obtidos neste trabalho indicam que a Seqüência Campinorte é paleoproterozóica. O contato entre ambas seqüiências, bem como 
destas com o Complexo Hidrolina, são falhas regionais que possibilitaram transporte tectônico da Seqüência Mara Rosa sobre a Sequiência Campinorte, e desta sobre o Complexo Hidrolina. Lineações minerais de baixo ângulo em rochas da Seqüência Campinorte indicam vergência de norte para sul durante o Paleoproterozóico. O segundo evento de deformação das rochas da área estudada é evidenciado por feições estruturais de estilo e cinemática caracterísiticos do ciclo Brasiliano. A existência de duas sequiências vulcano-sedimentares justapostas originadas em am- biente geotectônico de arco de ilha em tempos geológicos distintos. A proposta de um arco magmático paleoproterozóico que se estende ao longo do limite leste do Arco Magmático neoproterozóico de Goiás é compartilhada por Fischel et al. (2001).

Agradecimentos Aos revisores da RBG pelas sugestões ao original e ao Laboratório de Geocronologia do Instituto de Geociências da Universidade de Brasília pelas análises geocronológicas.

\section{Referências}

Barbosa O., Baptista M.B., Braum O.P.G., Cotta J.C. 1969. Geologia e Inventário dos Recursos Minerais da Região Central de Goiás (Projeto Brasília). DNPM, 148 p.

Carmo S.D. 1978. Planejamento e execução do Projeto Geofísico BrasilCanadá. In: SBG, Congr: Bras. Geol., 30, Recife, Anciis, 5:2233-2247.

Dantas E.L., Jost H., Fuck R.A, Brod J.A., Pimentel M.M., Meneses P.R. 2001. Proveniência e idade deposicional de seqüências metavulcano-sedimentares da região de Santa Terezinha de Goiás, baseada em dados isotópicos Sm-Nd em monocristal de zircão. Rev. Bras. Geoc., 31:329-334.

Fischel D.P., Pimentel M.M., Fuck R.A., Armstrong R. 2001. U-Pb SHRIMP and Sm-Nd geocronology of the Silvânia volcanics an Jurubatuba granite: juvenile Paleoproterozoic crust in the basement of the Neoproterozoic Brasilia Belt, Goiás, central Brazil. An. Acad. Bras. Cienc., 73:445-460.

Jost H., Fuck R.A, Brod J.A., Dantas E.L Meneses P.R., Assad M.L.L., Pimente M.M.,Blum M.L.B., Silva A.M., Spigolon A.L.D., Maas M.V.R., Souza M.M., Fernandez B.P., Faulstich F.R.L., Mcedo Junior P.M., Schobbenhaus C.N., Almeida, L., Silva A.A.C., Anjos C.W.D., Santos A..P.M.R., Bubenick A.N., Teixeira A.A., Lima B.E.M., Campos M.O., Barjud R.M., Carvalho R., Scislewski L.R., Sarli C.L., Oliveira D.P.L. 2001. Geolgia de terrenos arqueanos e proterozóicos da região de Crixás-Cedrolina, Goiás. Rev. Bras. Geoc., 31:315-328.

Kuyumjian R.M. 1989. Geoquímica e significado do posicionamento geotectônico de rochas plutônicas da região de Chapada, Goiás, Brasil. In: SBGq-CPRM/DNPM, Congr. Bras. Geol., 33, Rio de Janeiro, Anciis, 195-201.

Kuyumjian R.M. 1994. A sequência Mara Rosa na região de Chapada, Goiás. In: SBG, Núcleo Brasília, Bol. Informativo, 17(1-2):34-38.

Kuyumjian R.M. 2000. Magmatic arc and associated gold, copper, silver and barite deposits in the State of Goiás, Central Brasil: characteristics and speculations. Rev. Bras. Geoc., 30:285-288.

Kuyumjian R.M., Oliveira C.G., Campos J.E.G., Queiroz C.L., Barbosa I.O., Chimpliganond C.M., Costa F.S., Cruz A.B., Cunha S.A.r., Lima L.B., Lopes R.O., Fava N., Viana S.a. 1977. Projeto Chapada. Instituto de Geociências, UnB, Trabalho Final de Graduação, 90 pgs.

C.M., Costa, F.S., Cruz, A.B., Cunha, S.A.R., Lima, L.B., Lopes, R.O., Fava, N., Viana, S.A. 1977. Projeto Chapada. Inst. de Geociências, Universidade de Brasília, São Paulo, Trabalho de Graduação, 90p.

Lacerda H. 1986. As mineralizaçãoes auríferas da região de Mara Rosa (GO). Rev. Bras. Geoc., 16:274-284.

Machado E.C. \& Oliveira C.C. 1981. Novas considerações e integração geológica na região Pilar-Crixás e Mara Rosa-Porangatú. In: SBG/
Núcleo Centro-Oeste, Simp. Geol. Centro-Oeste, I, Ata, 300-320.

Moody J.D. \& Hill M. 1956. Wrench-Fault Tectonics. GSA Bull., 67:12071248.

Oliveira C.G.\& Pimentel M.M. 1998. Geology of the northern part of the Hidrolina Dome and Sm-Nd isotopic data for metavolcanic and granitoid rocks in the Campinorte region, Goiás, Central Brazil. In: UFOP/IBTA, International Conference, Precambrian and Craton Tectonics, Ouro Preto, M.G., Abstracts, 55-56.

Oliveira C.G., Queiroz C.L., Pimentel M.M. 2000. The ArenópolisMara Rosa gold-copper belt, Neoproterozoic Goiás Magmatic Arc. Rev. Bras.Geoc., 30:219-221.

Pearce J.A., Harris N.B.W., Tindle A.G. 1984. Trace element discrimination diagrams for the tectonic interpretation of granitic rocks. J. Petrology, 25:956-983.

Pimentel M.M. \& Fuck R.A. 1992. Neoproterozoic crustal accretion in central Brazil. Geology, 20:375-379.

Pimentel M.M., Whitehouse M.J., Fuck R.A, Machado N. 1997. The Mara Rosa arc in the Tocantins Province: further evidence for Neoproterozoic crustal accretion in central Brazil. Prec: Res., 81:299-310.

Queiroz C.L. 1995. Caracterização dos domínios estruturais e da arcuitetura do greenstone belt de Crixás; GO. Instituto de Geociências, Universidade de Brasília, Brasília, Dissertação de Mestrado, 117 p.

Ramos Filho W.L., Araújo Filho J.O., Kuyumjian R.M. 2004. Características da ambiência estrutural do depósito de Chapada, Goiás. Rev. Bras. Geoc.,33:09-116.

Ribeiro Filho W. \& Lacerda Filho J.V. 1985. Geologia da região de Santa Terezinha. In: SBG/Núcleo Centro-Oeste, Simp. Geologia CentroOeste, 2, Ata, pp.: 174-184.

Siqueira D.C.L.B., Cortes I.M.A., Sá J.A.G. 1987. Mapa geológico do Estado de Goiás (escala 1:1.000.000). MME/DNPM/DGM. Brasília.

Thompson R.N., Morrinson M.A., Hendry G.L., Parry S.J. 1984. An assessment of the relative roles of crust and mantle in magma genesis: an elemental approach. Phil. Trans. R. Soc. London, A310:549-590.

Viana M.G., Pimentel M.M., Whitehouse M.J., Fuck R.A, Machado N. 1995. O arco magmático de Mara Rosa, Goiás: geoquímica e geocronologia e suas implicações regionais. Rev. Bras. Geoc., 25:111123.

Manuscrito A-1370

Recebido em 27 de setembro de 2002

Revisão dos autores em 18 de abril de 2004

Revisão aceita em 20 de maio de 2004 